\title{
Articulación vertical de la inversión urbana en el nordeste argentino. Reflexiones sobre la experiencia del Banco Mundial durante la década del ' $90^{* * *}$
}

\begin{abstract}
This paper analyses vertical articulation of public investment model, deployed under Structural Adjustment Program during the 1990s in Argentinian north-east. Proposed analysis considerates theoretical debate about modern development theories applied therefore experienced by international finance agencies like World Bank, and its associated donors. It is argued that under the current lending trends it is unlikely to reach a sustainable and democratic development. Conversely, these policies not only increased the country's debt, it also exacerbated the gap between planning agenda and social expectation and demands. It concludes by exploring the urgent need to develop a horizontal articulation of urban management as reliable tool to encourage democratic local development.
\end{abstract}

Keywords: Structural adjustement, urban investment, Argentina.

\section{Resumen}

Este artículo analiza el modelo de articulación vertical de la inversión urbana pública, implementada en el nordeste argentino a partir de las reformas estructurales realizadas por el gobierno nacional durante la década del '90. El análisis propuesto considera el debate teórico sobre el desarrollo moderno, y los fundamentos y experiencias que propiciaron la intervención de los organismos financieros internacionales sobre los países menos desarrollados, a través de programas crediticios. Se sostiene que, lejos de fundar nuevas formas de desarrollo sustentables y más democráticas, estas políticas no sólo han contribuido al endeudamiento externo de estos países, sino que han profundizado la separación entre planeamiento y demandas sociales. Se concluye finalmente con una reflexión sobre la necesidad de alcanzar una articulación horizontal en la gestión urbana, como verdadero instrumento del desarrollo local.

Palabras clave: ajuste estructural, inversión urbana, Argentina. 


\section{Introducción}

$\mathrm{E}$ $n$ los inicios de la década de los '90, el Estado argentino realizó profundas reformas estructurales de corte neoliberal, que afectaron las formas y los contenidos de la política pública. Lejos de crear ámbitos más transparentes para el desarrollo y las inversiones en el campo de las obras públicas, éstas han seguido un proceso de decisión vertical en el cual los conglomerados urbanos han actuado como meros repositorios pasivos de un sinnúmero de programas y proyectos diseñados, en muchos casos, lejos de las necesidades reales de sus poblaciones. Han representado una alta inversión de capital basada en la generación de una cada vez mayor deuda externa, y han sido fuertemente impulsados por los organismos financieros internacionales. Pero estos programas y proyectos entraron transitoriamente en crisis a fines de diciembre del 2001, con el alzamiento popular que desbarrancó al gobierno elegido constitucionalmente en el año 2000.

A la luz de las negociaciones que el actual gobierno argentino está llevando adelante con estos organismos financieros internacionales, este artículo

* Profesor FAU/UNNE, investigador de la Secretaria General de Ciencia y Técnica/UNNE. Miembro fundador FORURBANO.E-mail: mabarreto@arnet.com.ar

** Co-editor de Cuaderno Urbano, FAU/UNNE. Miembro fundador FORURBANO. E-mail: jose.zavala@btinternet.com

${ }^{* * *}$ El presente artículo fue realizado en el marco del proyecto de investigación PI 652 de la Secretaría General de Ciencia y Técnica de la Universidad Nacional del Nordeste, denominado "Suburbanización residencial popular y pobreza. Hacia un mejoramiento participativo del espacio urbano público". Los autores queremos agradecer a las siguientes personas: a los funcionarios y trabajadores de las UEP y SUPCE de las Provincias de Chaco y Misiones que nos han brindado su valioso tiempo e información; a Patricia Galván, que ha contribuido a mejorar la fluidez de la lectura de este escrito; al evaluador anónimo que con sus críticas ayudó a esclarecer nuestras ideas y a expresarlas en mejores términos. Recibido a 14 de abril de 2003, aprobado el 20 de enero de 2004.

${ }^{1}$ La primera versión de este trabajo fue escrito a principios del año 2002, durante el gobierno interino del presidente Eduardo Duhalde. La presente -abril 2004- en cambio, cuenta con la incorporación de nuevos trabajos que realizamos desde entonces. Recibido a 14 de abril de 2003 , aprobado el 20 de enero de 2004. pone su atención sobre la continuidad y permanencia de tal esquema vertical en el manejo de los recursos financieros y la gestión de proyectos urbanos ${ }^{1}$. Las preguntas que guiarán su desarrollo serán las siguientes: ¿sobre qué base social se sustentarán las nuevas estrategias de desarrollo de inversiones en infraestructura económica -establecidas por los organismos financieros internacionales-, dado el actual contexto de alto protagonismo de la sociedad civil y la muy baja capacidad de disciplinamiento social de los partidos políticos tradicionales, que apoyaron el modelo neoliberal de desarrollo durante la década del ' 90 ? ¿Será posible alcanzar una articulación horizontal de las decisiones en la planificación de las obras públicas, incorporando a la sociedad civil en un intento de democratización del uso de los recursos financieros comunes?

Las Unidades Ejecutoras Provinciales (UEP) fueron, durante la década pasada, las terminales locales de la articulación vertical que el Banco Mundial adoptó como medio para llevar adelante la ejecución de sus programas y proyectos. El trabajo analiza los casos de las UEP de las provincias de Misiones y Chaco, respectivamente, en el marco de una revisión de las ideas y políticas mundiales sobre el desarrollo. El trabajo concluirá reforzando la idea de que, lejos de fundar nuevas formas de desarrollo más sustentables y democráticas, estas políticas han profundizado la separación entre planeamiento y demandas sociales, abogando por una articulación horizontal de la gestión urbana como instrumento valedero de desarrollo local.

\section{La idea del desarrollo moderno y el avance del liberalismo}

Analizar detalladamente los factores que facilitaron la hegemonía del paradigma liberal en el campo de las teorías del desarrollo escapa largamente al interés de este trabajo. Sí, en cambio, se presentarán los argumentos iniciales que fundamentaron las políticas de desarrollo de los organismos financieros internacionales bajo influencia del paradigma liberal. Para una mejor comprensión de este propósito, se analizarán las principales razones que propiciaron un vacio en el campo de las teorías del desarrollo y que facilitaron el establecimiento de una concepción del desarrollo basado en las leyes del 
mercado, impulsada por los únicos que resultaron ilesos de las refriegas intelectuales durante las décadas de los'60 y'70: los neoliberales.

El Banco Mundial irrumpió en el escenario mundial en 1972 (Pugh, 1992). Su irrupción fue sin demasiadas pretensiones teóricas y con ideas muy pragmáticas acerca de cómo se debería afrontar el problema de la pobreza mundial. Su intervención se centró exclusivamente a escala de proyecto y sobre situaciones específicas, con el objetivo de mejorar las condiciones de los pobres, pero sin inmiscuirse en las causas generales que producían la pobreza. En los campos académicos y consultores de los '80, este cambio en la percepción del problema se publicitó con la expresión "solucionática" en contraposición a la de "problemática", que habitualmente empleaban las teorías que por entonces trataban sobre las causas de generación de la pobreza mundial. A partir de entonces, el foco comenzó a centrarse en cómo solucionar situaciones particulares sin tener en cuenta el contexto en el que ellas se inscribían, partiendo siempre desde tabula rasa. Este proceso de vaciamiento teórico del problema del desarrollo tuvo principalmente una base económica financiera que establecía -y aún establece- el qué y el cómo se genera una solución, despojando de todo otro contenido a las acciones para el desarrollo. Pero antes de llegar al presente, se analizarán brevemente las condiciones que facilitaron este vacío de argumentos en el campo de las teorías de desarrollo.

A finales de los años '60, las ideas acerca de cómo se debía desarrollar un país estaban polarizadas, principalmente, entre marxistas y desarrollistas, los cuales no diferían demasiado entre sí acerca de los medios para alcanzar el desarrollo; ambos apostaban a la producción industrial masiva a través de unidades monopólicas de gran escala y una política centralizada de planificación, diferenciándose eso sí en las formas y fines de alcanzar el desarrollo: mientras los primeros apostaban al Estado como único motor de la producción y a la sociedad socialista como fin, los segundos lo hacían sobre las grandes corporaciones privadas monopólicas, protegidas y reguladas desde la planificación estatal centralizada y fuertemente identificadas con las economías nacionales (Reich, 1993), con la finalidad última de alcanzar un capitalismo más equitativo en la relación entre el capital y trabajo. Mientras que los primeros tenían en el Estado centralizado soviético su modelo de referencia, los segundos confiaban en el keynesianismo económico y el Estado benefactor europeo o el New Deal norteamericano como forma para alcanzarlo.

Sin embargo, la persistencia de la pobreza en América Latina y el Tercer Mundo en general condujo, tanto a los marxistas críticos de las ideas venidas de Moscú -bautizados como "neo marxistas"y a los críticos del modelo desarrollista en estas latitudes-como la CEPAL-a elaborar la Teoría de la Dependencia para dar cuenta de tales persistencias. Esta teoría argumentaba que el desarrollo de los países pobres no se alcanzaría siguiendo los mismos caminos de los países desarrollados, fueran éstos los socialistas o los capitalistas, porque la pobreza que los afectaba era precisamente una consecuencia de la forma de desarrollo seguida por aquellos, basada en la explotación de los recursos de estos países y en la dependencia financiera y de productos manufacturados que éstos tenían de las naciones desarrolladas. Así planteadas las cuestiones, para esta teoría el subdesarrollo no consistía sólo en una falta de desarrollo, sino en una consecuencia de éste; es decir, constituía la otra cara de una misma moneda. Por lo tanto, su superación no consistía sólo en una cuestión de tiempo -el necesario para lograr la industrialización-, sino en replantear el propio concepto del desarrollo (Nun, 2001).

Entre otras cosas, los teóricos del subdesarrollo argumentaban que las empresas multinacionales imponían un patrón de consumo universal que no tomaba en cuenta las condiciones locales sobre las que ellas actuaban (paradójicamente, este argumento presentado como crítica fue retomado como virtud por los globalizadores durante los '80 y '90). También argumentaban que estas corporaciones priorizaban el uso de tecnologías de capital intensivo en regiones donde abundaba fuerza de trabajo vacante; que aseguraban sus ganancias imponiendo productos elaborados por sus casas matrices; que contaban con baja participación de trabajo local en su producción; y además, que se involucraban en la política local como medio de protección de sus intereses. En cambio, los desarrollistas que planteaban la participación de los estados nacionales como condición primordial para alcanzar el desarro- 
llo en el marco del capitalismo, promovían la inversión social en paralelo a la inversión física, como medio para garantizar la equidad social. Dentro de esta concepción siempre primó la idea de que la inversión en obras de infraestructura estaba estrechamente vinculada al incremento del PBI de una nación.

Sin embargo, mientras el mundo académico se debatía entre estas ideas y los políticos mantenían una posición pendular, los pobres seguían igual. Así fue que el desgaste tocó por igual a las puertas de los que discutían cómo se debía desarrollar un país y un gran impasse se abrió por entonces en los estudios acerca de este tema.

En el período comprendido entre 1950 y 1970 , lapso de existencia de estas teorías, quedó demostrado que poco se había avanzado en este campo a pesar de los aportes teóricos mencionados, debido -entre otras razones- a las evidencias que surgían de la aplicación de los modelos de desarrollo por ellas generada. Doscientos años atrás, la relación entre el índice de ingreso entre los países ricos y los países pobres era de 1,5:1; en 1960, de 20:1; en 1980 esta relación ya se había elevado a 46:1, arribando en 1989 a 60:1 (World Bank, 1991; Schurman, 1993). Sin duda que el argumento central en las pasadas décadas, atribuyendo al trickle-down un silencioso pero efectivo mecanismo de redistribución dentro del esquema capitalista de producción, falló definitivamente.

Schurman (1993) argumenta que el vacío que se había instalado en el campo del desarrollo a mediados de los '80 impulsó a distintos autores a analizar esta crisis, la cual se vio favorecida por siete razones:

- como la distancia entre países ricos y pobres en términos de ingresos era muy grande, resultaba imposible cerrar esa brecha, cualquiera sea la estrategia que se emplease. Recuérdese que a inicio de la década de los '90 América Latina tenía un índice anual de crecimiento per cápita de entre 1,3 y 1,6 y que, por lo tanto, le demandaría alrededor de 150 años alcanzar la mitad del crecimiento per cápita de los países occidentales ricos.

- Los países en vías de desarrollo en los '80 dirigían sus acciones a políticas e inversiones de corto plazo, para que estas ayuden a reducir sus penurias de alto endeudamiento externo, lo cual le imposibilitaba el trazado de políticas de mediano y largo plazo, que son las bases del crecimiento sostenido.

La aceptación del impacto que sobre el ambiente ha tenido -y tiene- el crecimiento económico, ha llevado a quienes promueven la idea de un desarrollo sostenible a argumentar que igualar el concepto de crecimiento económico al de desarrollo no es conducente para los países del tercer mundo, dado que significaría enfrentar una catástrofe ecológica que puede ser evitada. La hipótesis de crecimiento cero apareció entonces como una opción, aunque todavía no existan fundamentos ciertos al respecto dentro de las desacreditadas teorías del desarrollo.

La deslegitimación del socialismo como vía para enfrentar el subdesarrollo, que sobrevino después de considerar que las posiciones de los marxistas y neo-marxistas no eran suficientemente consistentes respecto de una estrategia alternativa al desarrollismo moderno.

La profunda convicción de que el mercado mundial abarca a todos, y que no puede ser enfrentado usando las teorías del desarrollo que están orientadas a escalas nacionales, relegando al Estado-nación a una pequeña función que no tiene incidencia de peso en el contexto global.

El reconocimiento creciente de la diferenciación entre países y regiones del denominado Tercer Mundo, conducente a considerar como no conveniente la elaboración de teorías homogéneas del desarrollo.

El avance de la escuela post-moderna dentro de las ciencias sociales, que impuso su crítica a las grandes narrativas (capitalismo, socialismo, comunismo), y cuyo argumento se basó en negar la existencia de una realidad común externa al mundo subjetivo de los individuos, también ha restado sentido a las ideas sobre el desarrollo, debido precisamente al carácter de metadiscurso de estas teorías. 
A finales de los '80, el único grupo que no había sido afectado por esta crisis -tal vez por su marginalidad en esa época- fue el de los neoliberales, adherentes a la ideología de la economía de mercado. La crisis petrolera de mediados de los '70, que aceleró el proceso de readecuación del Estado benefactor y puso en duda el paradigma de la modernidad al cual aquellas teorías del desarrollo estaban ligadas, favoreció al establecimiento de estas ideas, basadas en la convicción de que el desenvolvimiento de la economía de mercado estimularía el desarrollo en las otrora regiones coloniales del planeta.

Pero fue recién a principios de los '90 cuando los organismos financieros internacionales -tales como el FMI y el BM- llegaron a un acuerdo conceptual sobre una política común de desarrollo para los países deudores bajo este nuevo paradigma. El encargado de sintetizar casi diez años de experiencia en la aplicación de las nuevas políticas de desarrollo para ambas instituciones fue Williamson (1990), mediante el "acuerdo de Washington", en cuyo contenido se establecieron las bases económicas que deberían seguir las diferentes naciones para desarrollarse: la disciplina fiscal; la utilización del gasto público para promover el alto crecimiento y una redistribución de los ingresos; la privatización de las empresas estatales; la liberalización de los tipos de interés, los tipos de cambio, el comercio y la inversión extranjera directa; la eliminación de los obstáculos a la libre competencia; la reforma fiscal y la garantía de los derechos sobre los bienes.

Este nuevo conjunto de ideas creía, sin embargo, que la transición hacia el pleno desarrollo de estas regiones del mundo debía ser atendida mediante empréstitos financieros de los países más desarrollados a los menos, que contribuyan a crear las condiciones territoriales del desarrollo. En este contexto es donde surgieron los organismos crediticios internacionales especializados en la financiación de proyectos específicos de desarrollo y atención social. Es indudable que en la conformación de este nuevo esquema de organización de la economía mundial pesó la solución de la crisis económica mundial de mediados de la década del ' 70 mediante la expansión territorial y temporal del sistema capitalista de producción (Harvey, 1998).

\section{La construcción del paradigma de intervención de los organismos internacionales}

En 1972, el Banco Mundial inició su etapa de inversión en ciudades, con la consigna de "aprender de la experiencia" (Cohen, 2001), y sin inmiscuirse en pensamientos globales ni discusiones sobre cómo reducir la pobreza; simplemente-como ya se dijo-, actuando mediante acciones circunscriptas a proyectos en el marco de intervenciones acotadas. El primer proyecto que esta institución impulsó fue conocido con el nombre de Mark I (Pugh, 1992), y consistió en el financiamiento de obras para proveer de agua y de electricidad a los pobres de la ciudad de Calcuta, donde el $60 \%$ de la población vivía en villas de emergencia. Realizadas las obras y pasado un cierto tiempo, el proyecto mostró que de nada valían las inversiones realizadas si el municipio no contaba con los recursos económicos para el mantenimiento de las redes instaladas. La principal consecuencia de aquella experiencia piloto fue el aumento del número de casos de enfermedades hídricas en esa ciudad.

El Banco rectificó este error, pero no en Calcuta sino en su siguiente proyecto en la ciudad de Madras, también en India. El Mark II contaba ya con una unidad ejecutora-con técnicos seleccionados por el Banco, por su capacidad y experiencia- para que supervisara la inversión y sugiriera las modificaciones institucionales, financieras y económicas que el municipio debía realizar para obtener los fondos específicos que el mantenimiento de las obras realizadas requería. Transcurrido un tiempo, el Banco concluyó que no bastaba con la adecuación institucional de la municipalidad, ya que había otros límites estructurales que afectaron al proyecto, como el aumento especulativo de los precios de los terrenos donde se iba a desarrollar el proyecto. Esta situación llevó a la institución a un proceso de negociación con los propietarios, lo cual prolongó por un largo tiempo su culminación. Así, el Mark II, iniciado en 1976, concluyó sin muchos éxitos, recién en 1983.

El Mark III, lanzado en Bombay en 1977, incorporó las lecciones aprendidas en las experiencias anteriores. Este nuevo programa contempló ya la adecuación de la legislación para reducir las trabas 
que imponían los códigos de planeamientos y de construcción al desarrollo del proyecto, como así también las modificaciones de ciertos impuestos locales, la reducción de controles al mercado de alquileres y la reducción del gasto municipal. El cumplimiento de todas estas cuestiones fue una condición necesaria para que el Banco liberara los créditos para financiar las obras de infraestructura (Zavala, 2002b). El Mark III no hizo un solo desembolso de fondos hasta bien entrado 1984, cuando el Banco entendió que el municipio de Bombay había hecho todas las reformas institucionales sugeridas por ellos. A través de esta experiencia el Banco aprendió cómo coercer a sociedades enteras -o al menos a sus líderes más ambiciosos- mediante sus créditos que aseguraran las obras necesarias para el desarrollo de la infraestructura económica en el largo plazo.

Aquel programa fue en cierta medida la última prueba piloto, ya que luego de esta experiencia, los organismos financieros internacionales extendieron sus acciones a 55 países, y en forma paralela a este lanzamiento masivo, configuraron lo que se denominó Programa de Ajuste Estructural (PAE). Los primeros países que experimentaron su aplicación fueron los ubicados al sur del Sahara durante la década de los ' 80 , con resultados desastrosos para los sectores más pobres de sus poblaciones. En Argentina, el PAE se inició a mediados de 1991 (García Delgado, 1994), en concordancia con lo establecido en el Consenso de Washington. Su comienzo fue a partir de la sanción de una serie de decretos de necesidad y urgencia que reglamentaron las dos leyes votadas por el Congreso de la Nación en agosto de 1889, año en que asumió como presidente Carlos Menem -la Ley 23.696 de Reforma del Estado y la 23.697 de Emergencia Económica. El decreto de mayor importancia fue el 2284/91, que marcó las bases de la Reforma del Estado en siete capítulos (Honorable Senado de la Nación, 1996). Los lineamientos generales de la reforma propusieron un cambio fundamental en el rol del Estado argentino: que éste deje de ser productor de bienes y servicios económicos y se transforme exclusivamente en productor de bienes sociales (Alexander, 2000), abandonando su antiguo papel de mediador social y limitándose a regulador de las fuerzas del mercado, bajo el supuesto de que éstas son más eficientes en la producción y distribución de dichos bienes y servicios.

La "ventaja" que tuvo Argentina respecto a las experiencias anteriores fue que ya se subsanaron los errores cometidos en África mediante el ajuste y coordinación de políticas entre el FMI y el BM. El trabajo teórico de Williamson (1990) ciertamente ayudó al proceso de unificación de políticas. El traslado de sus preceptos a los nuevos programas generó un cambio sustantivo en las relaciones entre los organismos internacionales y los gobiernos nacionales. En términos prácticos, a los países que aplicaban las recomendaciones del Consenso de Washington les correspondía una contrapartida de inversiones en infraestructura económica que se materializaban en el otorgamiento de los créditos del BM y otros organismos financieros regionales.

El nuevo esquema implementado en la Argentina generó al principio un período de expansión económica (1991-1993) por la combinación de los siguientes factores:

reducción del gasto del Estado y superávit fiscal favorecido por la privatización de las empresas públicas productoras de bienes y servicios económicos.

- La apertura del mercado financiero generó un flujo de inversiones extranjeras en forma de capitales de riesgo.

- La apertura importadora mediante reducción de barreras comerciales trajo aparejada una caída en los precios de los bienes y servicios.

Pero a pesar de que el PAE mostró signos positivos inmediatos, estaba basado en una debilidad estructural evidente, ya que por ejemplo, los montos de egresos en concepto de pago de deuda externa en intereses y capital superaban a los de ingresos en concepto de desarrollo, que por otra parte eran inversiones que no favorecían el crecimiento económico necesario para cerrar la brecha deficitaria. Además, el superávit fiscal era alcanzado mediante la restricción de los gastos sociales que acompañaron al proceso de descentralización, que transfirió responsabilidades a las provincias y municipios sin los recursos que ellas demandaban. De manera que el PAE sólo tuvo resultados alentadores mientras el proceso 
de privatización generó ingresos suficientes a las arcas del Estado a través de la venta de empresas estatales y la reducción de subsidios. Sin embargo, su debilidad estructural -impuesta por los organismos internacionales de crédito y aceptada por el gobierno federal- tarde o temprano iba a colapsar, debido a que estaba basada en ingresos de capitales por vía de inversiones directas o por vía de endeudamiento privado y estatal, y no por el crecimiento de la economía real. Así, el flujo de capital fue reduciéndose cada vez más, hasta el colapso definitivo de la economía argentina en el 2001.

En resumen, el PAE no sólo constituyó cambios significativos en el gerenciamiento de las relaciones entre todos los niveles de la organización estatal (nación-provincias-municipios) merced al proceso de descentralización de competencias, sino que además generó un cambio sustancial en la relación entre el Estado, la economía y la sociedad argentinos, ya que el Estado dejó de prestar los servicios sociales que en forma constante lo había hecho desde medio siglo atrás. Las consecuencias negativas de esta trasformación no fueron inmediatas -entre otras razones, por la velocidad en que fueron realizadas-, pero no tardaron demasiado en llegar porque una vez concluidas, nada reemplazó lo que había anteriormente, $y$ las expectativas puestas sobre los efectos de la "mano invisible" del mercado, proclamada por los neoliberales, nunca se concretaron.

\section{El ajuste estructural de los '90, descentralización municipal y los cambios en la gestión urbana}

El PAE se materializó mediante una sucesión de leyes que determinaron los mecanismos de acción que la estrategia perseguía. La Ley de Convertibilidad fue una pieza clave en todo este proceso; prohibía el financiamiento del gasto publico vía emisión monetaria. Por lo tanto, el Estado federal, las provincias y algunos municipios tenían las alternativas de cubrirlo vía impuestos - que no estaban autorizados a aumentar- 0 a través de la venta de activos y endeudamiento. Esta última opción fue la más extendida. El argumento esgrimido era que el Estado había sido muy irresponsable en manejar su política monetaria y que siempre utilizó esta herramienta para cubrir su déficit. Con el endeudamiento como opción de financiamiento del déficit se argumentaba que el Estado sería más precavido, ya que tendría que negociar con sus acreedores las condiciones y los fines del capital demandado. En otras palabras, los acreedores demandarían condiciones ciertas de recuperación de sus inversiones, lo que redundaría en beneficio de toda la sociedad, ya que reduciría prácticas ilegales del uso de los recursos públicos -al menos en teoría. Se abría así un proceso que, como señalamos antes, generó grandes expectativas, dado que finalmente los créditos serían utilizados para realizar programas y proyectos específicos con posibilidades ciertas de concreción y no para engrosar las arcas generales del Estado, considerado ineficiente, como ocurría anteriormente. De esta manera, el desarrollo del país se condicionaba a la obtención de créditos internacionales.

Uno de los fines de la Ley de Reforma del Estado argentino dictada en el marco del PAE, fue promover una mayor participación de los municipios a partir de la descentralización de competencias (Zavala, 2001). Esto se realizó siguiendo indicaciones de los organismos internacionales de crédito, que habían iniciado esta experiencia a escala mundial unos quince años antes, en el marco de las crisis de los estados benefactores y de la necesidad de su rediseño. Según Ramírez (1997), en 1990 más de 75 países con poblaciones de entre 5 a 12 millones de habitantes habían comenzado a transferir algunas formas de poder desde el Estado nacional a los municipios.

A comienzos de los '90, el Estado argentino y los organismos financieros internacionales aplicaron el Programa de Saneamiento Financiero y Desarrollo Económico de las Provincias Argentinas (PROVINCIAS I), para promover que las provincias y los municipios realizaran sus reformas fiscales y mejoraran la eficiencia del gasto en concordancia con el ajuste realizado por el gobierno federal. El otorgamiento de este programa fue concebido como premio a las provincias y municipios que realizaban las transformaciones fiscales en concordancia con lineamientos centrales. El financiamiento estuvo dirigido al desarrollo institucional e inversiones en obras de infraestructura; sin embargo, estas últimas fueron las que prevalecieron por sobre las demás, debido al alto rédito político que trajo aparejado la ejecución de las obras. Todos los subproyectos que lo com- 
pusieron fueron diseñados, implementados, supervisados y ejecutados por los gobiernos provinciales a través de unidades ejecutoras fuertemente controladas desde el orden nacional e internacional, y su financiamiento total alcanzó primero a los US\$ 400 millones, incluyendo las contrapartidas provinciales, del orden de los US\$ 175 millones. Luego, el Estado nacional gestionó un segundo tramo, denominado PROVINCIAS II, que tuvo un monto adicional de US\$ 321 millones, más las contrapartidas del Estado nacional y de las provincias, incorporándose también el BID y el Eximbank de Japón (Zapata, 1998). El monto total de los programas Provincias I y II en 1996 fue de US\$ 721 millones.

Estos programas sirvieron como puentes para la obtención de otros créditos; no sólo de las mencionadas instituciones financieras, sino también de otras tales como el Eximbank, que -merced a los mismoscomenzaron a operar directamente con las provincias argentinas (Zapata, 1998), y lograron de esta manera la extensión de su mercado de crédito a partir de una demanda cautiva. De esta manera, la descentralización del Estado siguió una estrategia de trasladar gastos del orden nacional a los niveles de gobierno provinciales y municipales que reunían las condiciones económico-financieras para absorberlos, reduciendo así el endeudamiento central e incrementando el de los gobiernos provinciales y municipales.

Los argumentos teóricos generales de descentralización del Estado tienen al menos dos concepciones: (a) como política a seguir cuando hay que defi- nir los niveles de gobierno para efectuar el gasto y recaudar los recursos, considerando que la población beneficiada por un bien público está determinada por las extensiones espaciales de dicho bien y que no todos los bienes públicos tienen el mismo alcance geográfico (Zapata, 1998); y (b) como delimitación y respaldo a las responsabilidades de las autoridades locales y como instrumento para potenciar la incorporación de las organizaciones comunitarias al poder político, propiciando una mayor democratización de las sociedades locales con la finalidad de reducir las desigualdades sociales y económicas en el nivel en el que los requerimientos son más apremiantes.

Para que esto último ocurra es imprescindible que ella surja de la propia demanda ciudadana. La política de descentralización argentina, en cambio, ha seguido a la primera de estas dos concepciones: fue realizada exclusivamente por imperativos externos tanto en respuesta a una exigencia de ajuste estructural de los recursos fiscales de la administración central (en la que ésta obró como una estrategia de "sacarse de encima" importantes funciones que representaban erogaciones fiscales considerables, y no como un proceso real de apertura participativa y de delegación de responsabilidades a niveles inferiores de la administración federal) como en garantía a una adecuada asignación de recursos a los programas y proyectos implementados. En otro nivel de lectura, este proceso de descentralización puede ser interpretado como una palpable demostración del avance de los organismos finan-

Cuadro 1. Argentina: gastos por sector y nivel de Gobierno, 1980/84-1994 (en porcentajes).

\begin{tabular}{|c|c|c|c|c|c|c|c|}
\hline Sector & $\begin{array}{c}\text { Gob. } \\
\text { Central } \\
1980-84\end{array}$ & $\begin{array}{c}\text { Gob. } \\
\text { Central } \\
1994\end{array}$ & $\begin{array}{c}\text { Gob. } \\
\text { Provinciales } \\
1980-84\end{array}$ & $\begin{array}{c}\text { Gob. } \\
\text { Provinciales } \\
1994\end{array}$ & $\begin{array}{c}\text { Gob. } \\
\text { Municipales } \\
1980-84\end{array}$ & $\begin{array}{c}\text { Gob. } \\
\text { Municipales } \\
1994\end{array}$ & Total \\
\hline $\begin{array}{l}\text { Educación } \\
\text { superior }\end{array}$ & 83,9 & 78 & 16,1 & 22 & 0 & 0 & 100 \\
\hline Saneamiento & 32,4 & 7,9 & 67,6 & 92,1 & 0 & 0 & 100 \\
\hline Vivienda & 13,5 & 6,5 & 75,4 & 69,6 & 11,1 & 23,9 & 100 \\
\hline $\begin{array}{l}\text { Bienestar } \\
\text { social }\end{array}$ & 65,9 & 16,2 & 34,1 & 83,8 & 0 & 0 & 100 \\
\hline $\begin{array}{l}\text { Servicios } \\
\text { urbanos }\end{array}$ & 0 & 0 & 3,6 & 6,7 & 96,4 & 93,3 & 100 \\
\hline
\end{tabular}

Fuente: Zapata (1998). 
cieros internacionales sobre el trazado de las políticas públicas nacionales y regionales, ya que de todos los proyectos que se ejecutaron en el marco de este proceso, puede decirse que representaron la expresión real y concreta de los avances de los organismos sobre las antiguas autonomías federales y provinciales -un análisis sobre las "nuevas" posiciones del BM es relativizado en Jones y Ward (1994).

Por otra parte, detrás del aparente criterio técnico con que fue presentada, primó siempre la dimensión política en su instrumentación (Zavala, 2001). Es que-como ya se dijo-, los programas Provincias I y II obraron a modo de incentivo para propiciar esta reforma; sus coberturas operaron como premio o castigo al grado de disciplinamiento seguido por los gobiernos municipales y provinciales en su instrumentación. En el caso de Argentina, esta variable ha generado un importante retraso en la implementación de las políticas descentralizadoras. En 1998, eran muchas provincias argentinas las que aún debían realizar gran parte de las reformas estructurales exigidas, porque ellas se encontraban condicionadas por prácticas corporativas de reproducción del poder político, tanto porque los gobiernos provinciales y municipales no querían cargar con el costo político de su instrumentación, o porque el gobierno central no pretendía realizar un traspaso real de recursos y competencias a los municipios con la finalidad de garantizar su continuidad política mediante el manejo de los recursos financieros.

De este modo, ninguno de los intereses puestos en juegos en las reformas del Estado federal apuntó a lograr una política real de descentralización. Para los organismos internacionales de crédito, la creación de la Unidad Ejecutora Central (UEC) dentro del Ministerio del Interior del gobierno federal y las diferentes Unidades Ejecutoras Provinciales (UEP) en las respectivas provincias argentinas, en conformidad con el organigrama funcional de gestión vertical ilustrado en la Figura 1, obró principalmente como una forma de garantizar el correcto uso de los recursos asignados, mientras que para los gobiernos central y provinciales, este modelo de gestión fue visto más bien como un nuevo recurso de reproducción política, basado en la explotación de la imagen de "gobiernos que realizan obras". Así, los gobiernos locales han tenido un grado limitado de injerencia que imposibilitó a la ciudadanía y a los actores loca- les conocer de antemano los proyectos a ejecutarse y decidir sobre la viabilidad y conveniencia de los mismos.

Este modelo tecnocrático de gestión política hegemonizó el discurso de los gobiernos nacional y provinciales, basándose en la eficiencia de su administración y la ejecutividad de sus realizaciones. Dentro de este discurso, el desempeño de las unidades ejecutoras jugó una pieza clave. Sin embargo, dada la discrecionalidad y los fines con los que se manejó la implementación de los programas, no han practicado otra cosa que una nueva forma de clientelismo, que se podría definir como "clientelismo tecnocrático". En su instrumentación, la dimensión política no ha sido excluida; la reconstrucción empírica de las condiciones en las que se establecieron las prioridades y los proyectos de desarrollo desde las unidades ejecutoras ponen en evidencia cómo la antigua práctica política se ha trasmutado, pero sin alterar la forma de participación de la sociedad civil en el poder político. Así, tecnocracia y democracia han corrido por caminos paralelos durante los ' 90 , sin contacto entre ellos pero con hegemonía absoluta de la primera sobre la segunda forma de gobierno.

\subsection{Introducción a los casos de estudios}

Los programas Provincias I y II fueron diseñados siguiendo los lineamientos del Banco Mundial expresados en Urban Policy and Economic Development. An Agenda for the 1990's (World Bank, 1991). El organigrama funcional empleado para llevar adelante estos programas es como lo muestra la Figura 1 (allí se resaltan los casos de estudios: las UPS de las provincias de Chaco y Misiones). La Unidad Ejecutora Central (UEC), creada dentro del Ministerio del Interior de la Nación a solicitud de los organismos internacionales de crédito y las Unidades Ejecutoras Provinciales (UEP) y Subunidades Provinciales de Coordinación para las Emergencias (SUPCE), creadas dentro del Poder Ejecutivo de los diferentes gobiernos provinciales durante este período, dependientes de esta Unidad Ejecutora Central, constituyeron un organigrama de funcionamiento de un modelo de gestión vertical que alteró la organización federal del Estado argentino. En este organigrama se observa claramente cómo los organismos internacionales de crédito y la 
nación precedieron a las provincias en las formas y modos en que éstas debían endeudarse, y también sobre qué sectores debieron dirigir sus endeudamientos, ya que estos programas funcionaron sobre la base de un menú preestablecido de programas y proyectos, sobre los cuales las Unidades Ejecutoras Provinciales debieron escoger en función de las necesidades de cada provincia, necesidades que curiosamente -en muchos casos- fueron determinadas por los propios consultores de estos organismos internacionales de créditos, u otros intereses, que poco tenían que ver con las necesidades reales de las sociedades locales.

Los programas Provincias I y II han tenido básicamente los siguientes componentes:
Catastro. Subproyecto tendiente a normalizar y modernizar el registro catastral a nivel provincial, con los objetivos de optimizar la recaudación fiscal y garantizar la propiedad privada dirimiendo y normalizando la tenencia de bienes inmuebles.

Programa de Inundaciones. Subprograma que consistió en series de terraplenes para proteger a las ciudades ubicadas dentro de los valles de inundación del río Paraná. Originalmente, iba a consistir en más de $1.500 \mathrm{kms}$. de terraplenes para proteger a todos los habitantes de la Mesopotamia argentina, basándose en las respuestas a situaciones similares implementadas por el Banco Mundial en el delta de Bangladesh y que representaron las faraónicas inversiones que caracterizaron los primeros yerros del $\mathrm{BM}$ en la década de los '70. Posteriormente, este

Figura 1. Organigrama funcional de la estructuración vertical del crédito internacional en Argentina.

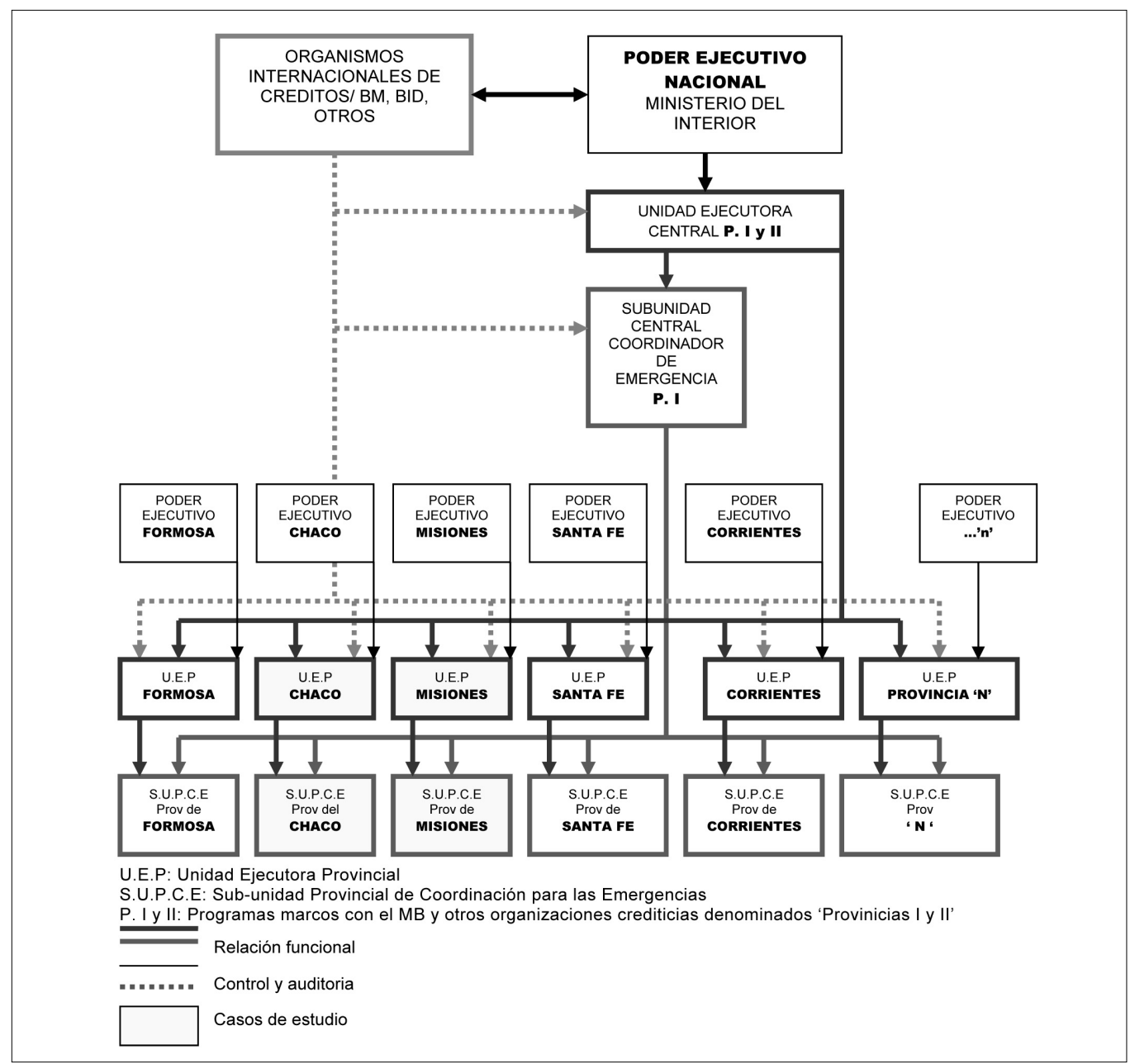


subprograma se redujo notablemente; bajo la denominación de Programa de Emergencia para las Inundaciones, entre 1992-1996 contó con un monto de US\$270 millones, y tuvo como objetivo principal restaurar la normal actividad económica y social de aproximadamente 4 millones de personas en la región afectada por las inundaciones, y suministrar un marco institucional sólido para la coordinación e implementación del programa global de préstamos de rehabilitación a la infraestructura dañada por esas inundaciones. Sus componentes fueron: (a) ejecución de subproyectos (obras nuevas y rehabilitación), obras de infraestructura de caminos, escuelas, hospitales, redes y tomas de agua, cloacas y drenajes pluviales, obras de mejoramiento y ampliación de defensas costeras de ciudades; y (b) financiación de subproyectos habitacionales (World Bank, 1992; Secretaría de Asistencia Financiera a las Provincias, 1999). Este fue un subprograma emblemático, con el cual el BM cobró notoriedad en Argentina, dado que fue anunciado con un gran despliegue publicitario por parte del gobierno nacional en respuesta a las críticas que habían causado la privatización de empresas nacionales. A partir de 1996, este programa fue renovado bajo la denominación de Proyecto de Protección Contra las Inundaciones y comprometió un monto de US\$ 420 millones, contando con los siguientes elementos: (a) instalación de refugios familiares de emergencia; (b) componentes de vivienda para favorecer la autoconstrucción; (c) mantenimiento y operación de un sistema de aviso temprano contra las inundaciones; $y$ (d) reforzamiento de la regulación del uso del suelo en condiciones con riesgo de inundación (World Bank, 1996).

Programa de Caminos. Este fue el de mayor inversión: el monto comprometido ascendió a US\$ 1.500 millones, fue ejecutado por las direcciones provinciales de vialidad y supervisado por las UEP respectivas. Este programa puso en evidencia el escaso raciocinio que tuvo la planificación federal desde el punto de vista de los intereses públicos, ya que a través del mismo se asumió una importante deuda pública para la construcción de caminos secundarios y terciarios provinciales, mientras que la red primaria de rutas nacionales fue concesionada al sector privado, asegurándose la rentabilidad de las empresas concesionarias a través de un subsidio bajo la forma de un canon anual. Así, la inversión pública favoreció doblemente la rentabilidad del sector privado e incrementó además los costos de transporte de la actividad productiva y la deuda pública, cuando lo lógico hubiese sido que el sector privado asumiera las inversiones a través de la rentabilidad garantizada por las concesiones realizadas.

Programa de Reforma Provincial. Este programa tuvo un monto comprometido de US\$ 300 millones y fue diseñado para promover los siguientes cambios: (a) recaudación de recursos propios mediante la fijación de metas de auditorías de contribuyentes y de mejoramiento de la administración de tributos; (b) control del gasto, tanto en los aspectos presupuestarios como en el de personal; preparación de leyes de participación municipal que privilegien a la buena administración y a la privatización de empresas públicas; y (c) privatización de bancos provinciales y municipales.

Fondo Fiduciario para el Desarrollo Provincial. Este fondo fue pensado con el objetivo de prestar apoyo financiero a las reformas del sector público argentino y promover el desarrollo económico de las provincias; el monto comprometido alcanzó a US\$ 1.250 millones.

Programa de Desarrollo Municipal. Este programa se implementó con el objetivo de contribuir al mejoramiento de la administración municipal, y dispuso de dos líneas: (a) desarrollo institucional; y (b) inversiones en proyectos municipales tales como rehabilitación de obras, adquisición de equipos y maquinarias, etc. (Zapata, 1998). Este programa requirió de ciertos requisitos de acceso que restringieron ampliamente su uso a los municipios más relegados o marginados regionalmente, atendiendo principalmente a los municipios de las ciudades capitales de provincia y acentuando aún más las inequidades internas ya existentes.

Estos fueron los principales componentes de los programas PROVINCIAS I y II, que tuvieron por finalidad propiciar la reforma del Estado argentino durante los '90. La finalidad de este artículo es analizar cómo este modelo de gestión vertical se instrumentó en las diferentes provincias argentinas a través del estudio de dos casos particulares: la provincia del Chaco y la provincia de Misiones, en la región nordeste de la Argentina. 


\subsubsection{El caso de la Unidad Ejecutora de la Provincia de Misiones}

A partir del menú prefijado de componentes que integraron los programas Provincias I y II, cada una de las UEP estableció las prioridades y los ejes sobre los cuales trabajar. El gobierno de la provincia de Misiones ha obtenido importantes beneficios de los mismos, particularmente en el área de inversiones viales: una de las más importantes prioridades fue la vialidad provincial. La construcción de caminos primarios y secundarios alcanzó varios cientos de kilómetros en esta provincia. Sin embargo, como ya se dijo, esta inversión no favoreció al transporte de la producción primaria regional y el acceso a los mercados por parte de sus productores, sino más bien a las concesiones de las rutas principales realizadas al sector privado para el cobro de peaje, como así también a la tecnocracia política y su reproducción en el poder (no sólo a través del uso electoral de las obras -cuyas fechas de inauguración casualmente siempre coincidieron con los períodos eleccionarios de esta provincia-, sino también al vínculo establecido entre gobierno y empresas ejecutoras para el financiamiento de estas actividades políticas, conexión denunciada por la oposición política en los medios de comunicación locales y nacionales).

Pero además estos proyectos no han estado debidamente ajustados a las necesidades reales de la sociedad local, ni coordinados entre sí. Por ejemplo, en la ciudad de Posadas, capital de la provincia, se ha construido una red vial que se adelantó en años a la demanda efectiva del tránsito de la ciudad, con el error técnico además de que un porcentaje importante de ella se construyó sin haberse realizado previamente el tendido de redes cloacales, de agua potable y desagüe pluvial, siendo una ciudad que tiene un promedio de 1.800 milímetros anuales de precipitación. Al poco tiempo de finalizadas estas obras viales, era frecuente encontrar operarios de otras empresas que -trabajando en el marco de otros proyectos- rompían el flamante pavimento construido para realizar las obras faltantes. Esta situación puso en evidencia que la selección de opciones brindadas por estos programas no fue realizada a partir de una planificación integral de las demandas urbanas y provinciales, sino más bien a partir de otros criterios, en algunos casos, político-electoralistas, y en otros, de simple obligatoriedad de utilizar los numerosos créditos disponibles a través de estos programas, que han conducido a un uso compulsivo de los mismos y han generado la realización de numerosas obras innecesarias.

Esto ha sido evidente en la informatización del sistema de catastro, que en términos prácticos ha traído más inconvenientes que ventajas, debido a que en lugar de favorecer el registro y la tasación de propiedades, ha generado innumerables inconvenientes al respecto, tanto por no contar el gobierno provincial con el personal técnico necesario para su manejo, como por la fuerte resistencia gremial que presentó el antiguo personal estable, debido al despido masivo de empleados que su instrumentación significaba.

Las inversiones innecesarias pudieron verse también en la utilización compulsiva de los fondos para Fortalecimiento Municipal, en la que se inventaron lugares de trabajo para consultores que generaron planes de ordenamiento urbano para pequeñas ciudades que no tendrán un crecimiento importante en el futuro, o que por el contrario, perderán población, mientras que importantes cantidades de ciudades y pueblos permanecen sin regulación alguna. La misma situación lo demuestra la realización de un sistema de semaforización inteligente en el casco céntrico de la ciudad de Posadas, construido con el objetivo de optimizar la economía urbana (Zavala, 2002a). Gracias a la asesoría de consultores expertos, esta ciudad tiene en la actualidad una red de 68 semáforos inteligentes que interpreta en tiempo real los flujos y adecua la frecuencia de los tiempos en cada punto de la red, al menos en teoría; en la práctica, esto significó un incremento en los accidentes de tránsito, y se multiplicaron los asaltos a los automovilistas, llegando al extremo que las actuales autoridades municipales están considerando otras alternativas (por ejemplo, que el sistema funcione en las horas comerciales y acotando a ciertas zonas de la ciudad, mientras el resto funcionaría con luz intermitente de prevención-Zavala, 2003). Cerca de US\$ 2 millones demandó esta obra, que al momento de escribir este trabajo había sido recepcionada con reservas por el gobierno municipal, existiendo pedidos de informes de parlamentarios sobre el origen del proyecto. 
Aunque esta no sea una exhaustiva descripción de todos los proyectos de la UEP de la provincia de Misiones, se puede concluir la revisión de la falta de planificación integral que guió la instrumentación de los programas Provincias I y II, mencionando la ejecución de una red de fibra óptica que fue realizada para enlazar a todas las reparticiones del Estado provincial ubicadas en la ciudad capital, con el objetivo de optimizar su administración provincial. Este proyecto ha puesto en evidencia una vez más la falta de criterios técnicos adecuados de planificación. En Europa, por ejemplo, esta tecnología fue empleada como una estrategia de desarrollo orientada a atraer inversiones privadas merced a la creación de potentes nudos de comunicaciones en ciudades económicamente deprimidas, ya que la red de fibra óptica y su conectividad a escala nacional e internacional ha sido considerada como factor que agrega valor y favorece la radicación de empresas que hacen uso intensivo de datos (bancos virtuales, centrales telefónicas internacionales). En el caso de Posadas, en cambio, fue utilizada sin propiciar ninguna sinergia económica, a un costo de US\$ 2 millones que los ciudadanos deberán hacer frente en el futuro.

\subsubsection{El caso de la Unidad Ejecutora de la Provincia del Chaco}

Este caso contrasta con el anterior, principalmente porque las inversiones estuvieron centradas en solucionar los graves problemas de las inundaciones periódicas que históricamente afectaron a la población de la Provincia del Chaco (AAVV, 1993). Sin embargo, las soluciones implantadas también tuvieron sus lados oscuros, producto de las debilidades de la excesiva focalización de las estrategias de desarrollo de los organismos internacionales de crédito, tendientes a no contemplar la integralidad del problema y a prestar poca consideración a las consecuencias a largo plazo de la instrumentación de esta concepción.

En 1993 se iniciaron en esta provincia las primeras inversiones en vivienda de emergencia para los afectados por las inundaciones periódicas, que consistieron en unidades habitacionales de 40 metros cuadrados, las cuales se entregaron bajo la forma de subsidio. Con ellas se implementó por primera vez en Argentina un criterio del Banco Mundial que antes había sido desoído por el gobierno nacional, y que significó la eliminación de los estándares constructivos que contenía el cuerpo normativo de la política pública de vivienda en el país. Sin embargo, esto no ocurrió en todos lados; de las siete provincias afectadas por las inundaciones, Entre Ríos, por ejemplo, no aceptó este programa de vivienda, aduciéndose que los entrerrianos se merecían algo más que "casa para perros", según rezaron las declaraciones del entonces gobernador de esa provincia a la prensa nacional en rechazo a este subprograma. En cambio, el gobierno chaqueño no objetó esta solución e implementó la construcción de las viviendas, las cuales contemplaban la participación de los usuarios en su ejecución, pero en el sentido que interpreta el BM este término; es decir, como un ítem componente del cómputo del proyecto, que sólo exige el aporte de una determinada cantidad de horas semanales de trabajo por parte del futuro usuario como forma de pago de su vivienda y no como una participación integral en el proceso de producción de la misma (que podría incluir, por ejemplo, su participación en el diseño para una respuesta más adecuada a sus necesidades). Para aquella fase de este proyecto, el programa habilitó US\$2,5 millones y se construyeron 514 unidades de vivienda, siendo el costo de la tierra y demás infraestructuras el aporte del gobierno provincial al proyecto. Una cuestión adicional a la implementación de este proyecto tiene que ver también con la contribución a la segregación social y segmentación del espacio urbano que generó la localización de estos conjuntos habitacionales de poblaciones pobres en áreas periurbanas desprovistas de las más elementales redes de infraestructura y servicios urbanos (Barreto \& Zavala, 2003).

Otro aspecto problemático de este proyecto fue el grado de solución efectiva que significó para la población afectada, ya que con la finalidad de evitar que la adjudicación de las viviendas no fuera manipulada por los dirigentes políticos en su habitual práctica clientelar, el proyecto fue articulado con la repartición pública de Defensa Civil, que tuvo a su cargo la confección de la lista de los beneficiarios, realizada al pie de viviendas inundadas para garantizar que las mismas lleguen a las personas afectadas. Sin embargo, ya en 1999 existían sospechas por parte de algunos funcionarios de que aquellas viviendas habían entrado al mercado, y que entre el 30 y $40 \%$ no pertenecía a los beneficiados originales. Nunca se 
tuvo el conocimiento fehaciente de cuál fue el destino de aquellos beneficiarios originales: si regresaron a sus anteriores lugares de vida después de haber cesado las inundaciones o si, con el dinero de la venta de las viviendas que se les habían otorgado, accedieron a otras de mejores condiciones habitacionales.

Dentro de este programa existieron otras líneas de inversión denominadas "estructurales", destinadas a la construcción de defensas de protección al área metropolitana del Gran Resistencia, sede de la ciudad capital de la provincia y que es un conglomerado de 300.000 habitantes aproximadamente. Estas obras consistieron básicamente en la construcción de un anillo protector compuesto de terraplenes elevados que definieron un polder dentro del cual la ciudad está quedando actualmente defendida, y obras de canalización de diferentes cursos de aguas, realizadas con el objetivo de evitar el incremento del caudal del río Negro, que surca el noroeste del área metropolitana y que periódicamente inundó a esta ciudad. Hay que destacar aquí que el gerenciamiento local del proyecto ha hecho un importante esfuerzo por incluir a todos los organismos públicos provinciales vinculados al problema, incluido uno de reciente conformación, la APA (Administración Provincial del Agua), que buscó incorporar una visión más integral del fenómeno de defensa e inscribió la problemática dentro de un marco más biótico, evitando caer en el sentido puramente ingenieril con el que ha sido tratado tradicionalmente el problema (aunque indudablemente ha sido muy difícil derrotar esta visión, debido a la seducción que la obra construida tiene sobre la dirigencia política y sus técnicos).

En otros trabajos (Barreto, 1993; 1998) se ha abordado también un estudio sobre las operaciones inmobiliarias especulativas que se realizaron en torno a las tierras que estas obras de defensa recuperaron para la ciudad y que han modificado gran parte de la estructura urbana de la ciudad de Resistencia, al definir nuevas áreas de alto valor ambiental y urbanístico, como así también nuevas áreas de exclusión y pobreza.

También deben tenerse en cuenta opiniones como la del geólogo local, Ramón Vargas, realizadas a propósito de la quebradura de un dique ocurrida en los años ‘ 80 y que inundó el $60 \%$ del área urbana de esta ciudad, con relación a las dificultades de oponerse a través de obras de ingeniería al comportamiento natural de los cursos de agua y del medio ambiente. En este sentido, solamente el tiempo demostrará la utilidad de estas obras.

\section{Articulación vertical y gestión urbana}

Con anterioridad a las reformas estructurales realizadas por el Estado argentino a solicitud de los organismos internacionales de crédito y desarrollo a principios de los '90, los empréstitos que tenían esta finalidad eran solicitados por el Estado y pasaban a engrosar las arcas fiscales generales, desde las cuales eran asignadas las partidas correspondientes a las reparticiones específicas en función de la planificación centralizada de un presupuesto público anual. La sospecha de que estos fondos eran frecuentemente malgastados o dilapidados por mala administración o corrupción -manifiesto por otra parte, en proyectos que muchas veces no terminaban de concretarse y dejaban obras inconclusas- llevó a los organismos internacionales de crédito y desarrollo a idear una nueva estrategia de gestión.

En este contexto, la articulación vertical que ha guiado durante la década de los '90 a los préstamos del Banco Mundial y el Banco Interamericano de Desarrollo para obras de infraestructura en estos países, tuvo como principal fundamento su eficiente asignación. A través de la exigencia a estos países para que crearan unidades ejecutoras específicas para su instrumentación, estos organismos buscaron corregir antiguas formas de desviación de fondos asignados genéricamente a las arcas de los estados nacionales. De esta manera, las llamadas unidades ejecutoras fueron creadas a pedido de estos organismos como reparticiones públicas específicas para mediar de manera directa la relación entre los organismos financieros internacionales y los gobiernos locales, con la finalidad de instrumentar los proyectos y monitorizar su correcta realización, obrando como brazo ejecutor de estos organismos crediticios.

Desde el punto de vista de la eficiencia económica, esta forma de organización parece lógica, ya que a través de la articulación vertical de decisiones mediante organismos específicos, el Banco Mundial y el BID 
pudieron garantizar que los fondos por ellos asignados realmente sirvieran para que las obras se realizaran y no para engrosar las arcas de los administradores locales, las de sus empresarios amigos o solventar las campañas políticas de los gobernantes locales. Sin embargo, y al margen de las nuevas formas de corrupción que se generaron a través de licitaciones infladas y arregladas con empresas privadas especializadas en la sobreexplotación obrera, merced a conformaciones flexibles y efímeras, lo que ha resultado desacertado para los intereses locales fue que este mismo principio de organización vertical también fue utilizado para la toma de decisiones con relación a los tipos de obras a financiar y para el diseño de los proyectos a realizarse.

En relación con la primera de estas cuestiones, los organismos financieros internacionales establecieron líneas de créditos con fines específicos, decidiendo unilateralmente sobre las prioridades de los diferentes gobiernos locales, brindándoles a éstos un menú prefijado de posibilidades que a su vez -generalmente- fueron decididas en las propias unidades ejecutoras, al margen de los consejos deliberantes y otros órganos de participación de la ciudadanía local, a la que solamente le correspondió, dentro de esta cadena vertical de decisiones, tributar o no los impuestos con los que se deben pagar las deudas contraídas a través de dichos empréstitos. En relación a las definiciones técnicas de las obras (diseño físico, viabilidad técnica, sustentabilidad tecnológica, etc.), fueron las unidades ejecutoras las responsables absolutas de las mismas, obrando ellas como verdaderos bunkers decisivos, cerrados en sí mismos y compuestos por técnicos muchas veces desvinculados de las realidades locales e incapaces por formación- de conocer sus prioridades o dar cabida a la participación de los futuros usuarios en la definición de las pautas directrices de los diferentes proyectos.

Como consecuencia de este esquema organizativo se puede listar una serie de obras realizadas en ambas provincias que resultaron inadecuadas $y / o$ innecesarias, tales como:

el sistema de semaforización inteligente antes mencionado, implantado en una ciudad donde el tránsito se demora por las calles rotas, $\mathrm{o}$ por los niños que limpian parabrisas y los vendedores ambulantes que utilizan las paradas de los automovilistas como fuente de recursos y medio de subsistencia. A este respecto, gran parte del problema del tránsito - debido a la escala de esta ciudad- se solucionaría simplemente reparando las calles laterales a las avenidas congestionadas.

- $\quad$ Sistemas mecanizados y centralizados de recolección y eliminación de residuos en ciudades donde existen importantes sistemas informales de recolección, y sectores sociales capacitados en reciclar basura con el fin de obtener alimentos y materiales para construir y equipar sus lugares de vida.

Escuelas diseñadas según esquemas de necesidades ideales que no se condicen con la realidad social de sus alumnos, en las que una importante porción de ellos asiste sólo para comer; o los equipamientos didácticos avanzados tales como computadoras, televisores y video caseteras -financiados por estos organismos internacionales- que deben pasar la mayor parte del tiempo bajo llave en las oficinas de las directoras, por temor a robos u otros actos vandálicos.

- Remodelaciones de plazas céntricas realizadas en ciudades como Resistencia, que tiene a más de la mitad de su población viviendo debajo de la línea de pobreza, etcétera, etcétera.

En el rol de responsables de las decisiones técnicas de los proyectos, las unidades ejecutoras actuaron como ámbitos de trabajo muy distanciados de las verdaderas necesidades de las poblaciones a las que asisten, y dependen de un esquema vertical de decisiones que imposibilita cualquier forma de participación de los usuarios de los proyectos con relación a su conveniencia y necesidad. Por otra parte, si bien han servido para garantizar la ejecución de las obras financiadas por los organismos internacionales de crédito - evitando la ineficiencia de épocas pasadas-, no fueron útiles para neutralizar la corrupción ligada a las obras públicas, colaborando en el despilfarro del dinero y el engrosamiento de la deuda. Además, al no partir de un diagnóstico de la realidad local y de una planificación integral, sino decidiendo sobre fondos con destinos preestablecidos y focalizados, no sólo han favoreci- 
do la ejecución de obras innecesarias y con falta de coordinación entre sí, sino que han desaprovechado un sinnúmero de recursos locales con los cuales se habrían solucionado muchos de los problemas por ellos atendidos, con costos muchos más bajos y apropiados al desarrollo de la sociedad local.

\section{Reflexiones sobre la viabilidad de una articulación horizontal en el planeamiento y gestión de nuestras ciudades}

En virtud de lo analizado hasta aquí y a la luz de que el gobierno argentino, después de sortear transitoriamente la crisis de diciembre del 2001, nuevamente se encuentra negociando con los organismos internacionales de créditos y desarrollo la continuidad de programas y la elaboración de proyectos para el desarrollo, este trabajo quiere advertir, por un lado, la inviabilidad de implementación de articulaciones verticales en la instrumentación de tales programas, como los que aquí se han analizado, en el marco del estado deliberativo en que se encuentra actualmente la sociedad. Por otro lado, se cometería un gran error de apreciación si no se considera la necesidad que existe de participar en las decisiones atinentes a la gestión pública en un marco de descentralización que se debe utilizar para fortalecer el ejercicio del gobierno local. Como los casos de estudios ilustraron, es precisamente lo opuesto lo que se ha instrumentado en la Argentina de los años '90. Ciertamente, nada indica que el esquema de articulación vertical se reconfigure en nuevas formas de articulación horizontal en la gestión urbana actual con la finalidad de democratizar las prioridades de intervención e incorporar los recursos sociales locales como verdaderos instrumentos de un desarrollo equitativo y equilibrado, en la medida en que no se replantee la forma de relación con los organismos internacionales de crédito y desarrollo.

\section{Referencias bibliográficas}

AAVV (1993). Cuadernos de Sociología Urbana, 1.

Resistencia (Argentina): Facultad de Arquitectura, Universidad Nacional del Nordeste.

Alexander, M. (2000). "Privatizaciones en Argenti- na”. Banco Mundial/Grupo de Trabajo de ONG sobre el Banco Mundial/Instituto de Investigaciones del Nuevo Estado, Privatizaciones e impacto en los sectores populares. Buenos Aires: Belgrano.

Barreto, M. (1993). "La producción de suelo urbano en el Gran Resistencia en torno de las inundaciones de 1982-1983". Cuadernos de Sociologia Urbana, 1.

(1998). "Producción de suelo urbano en el Área Sur de la ciudad de Resistencia durante la década del ' 80 ”. Ponencia presentada al XXII Congreso de la Asociación Latinoamericana de Sociología. Concepción (Chile), 12-16 de octubre de 1999.

Barreto, M. \& J. Zavala (2003). "Programa de vivienda rural e integralidad productiva en Chaco. ¿Mejoramiento del hábitat rural o primacía de reproducción política?". Vivienda ruraly calidad de vida en los asentamientos rurales. Memorias del IV Seminario Iberoamericano, Red XIV, E. del Cyted, Habyted. Puerto Montt, (Chile), 21-23 de octubre de 2002.

Cohen, M. (2001). "Urban assistance and the material world: learning by doing at the World Bank". Environment \& Urbanization, 13, 1.

García Delgado, D. (1994). Estado \& sociedad: la nueva relación a partir del cambio estructural. Buenos Aires: Tesis Norma.

Harvey, D. (1998). La condición de la posmodernidad. Investigación sobre los orígenes del cambio cultural. Buenos Aires: Amorrortu.

Honorable Senado de la Nación (1996). Informe argentino sobre desarrollo humano. Buenos Aires: Senado de la Nación Argentina.

Jones, G. A. \& P. M. Ward (1994). “The World Bank's 'new' Urban Management Programme: paradigm shift or policy continuity?”. Habitat International, 18, 3.

Nun, J. (2001). Marginalidady exclusión social. México: Fondo de Cultura Económica.

Pugh, C. (1992). "International finance and housing policies in developing countries". Cities, 9.

Ramírez, R. (1997). "Local governance model: descentralisation and urban poverty erradication”. London: Development Planning Unit, University College London (mimeo).

Reich, R. (1993). El trabajo de las naciones. Hacia el capitalismo del siglo XXI. Buenos Aires: Vergara. 
Schurman, F. J. (1993). Beyond the impasse. New directions in development theory. London: Zed Books.

Secretaría de Asistencia Financiera a las Provincias (1999). "Subprograma de Viviendas por autoconstrucción”. PREI AR 3521 BIRF.

Williamson, J. (1990). "What Washington means by policy reform”. Williamson, J. (dir.), Latin American adjustment: how much has happened? Washington, D.C.: Institute for International Economics.

World Bank (1991). Urban policy and economic development: an agenda for the 1990s. A World Bank policy paper. Washington, DC.: World Bank.

(1992). "Memorandum and recommendation of the President of the International Bank for reconstruction and development to the Executive Directors on a proposed loan in an amount equivalent to US\$ 170 million to The Argentina Republic for a Flood Rehabilitation Project”. Report No. P-
5852-AR. Washington, DC.: World Bank. (1996). Argentina flood protection project. Washington, DC.: World Bank.

Zapata, J. A. (1998). “Financiando la ciudad”. Rojas, E. \& R. Daughter (eds.), La ciudad en el siglo. Simposio de Buenas Prácticas en Gestión Urbana en América Latina y el Caribe. Banco Interamericano de Desarrollo.

Zavala, J. (2001). “Direccionamiento desde arriba sobre municipios del Chaco, Argentina, 19941995”. Revista de Ciencias Sociales Convergencia, 24.

(2002a). "Ciudad y tecnología". Diario El Territorio, 15 de enero. www.terrritoriodigital.com

(2002b). "Posadas entre Bombay y Calcuta". Diario Primera Edición, 12-13 de febrero.

(2003). "Semáforos inteligentes; cuando la parte del león emerge”. Diario El Territorio, 7 de agosto. www.terrritoriodigital.com 